\title{
Association of Directly Observed Prophylaxis with Sulfadoxine-Pyrimethamine for Prevention of Mother-to-Fetus Transmission of Malaria, Kananga, Democratic Republic of the Congo
}

\author{
Leon Mubikayi1,2, Mark Eakes³, David 0. Matson,3,4* \\ ${ }^{1}$ Christian Medical Institute of the Kasai, Tshikaji, Kasayi University, Western Kasai Province, Democratic Republic of the Congo \\ ${ }^{2}$ Kasayi University, Kananga, Western Kasai Province, Democratic Republic of the Congo \\ ${ }^{3}$ Graduate Program in Public Health, Eastern Virginia Medical School, Norfolk, Virginia, USA \\ ${ }^{4}$ Department of Pediatrics, Eastern Virginia Medical School, Norfolk, Virginia, USA \\ Email: ${ }^{D}$ avid.Matson@CHKD.org
}

How to cite this paper: Mubikayi, L., Eakes, M. and Matson, D.O. (2020) Association of Directly Observed Prophylaxis with Sulfadoxine-Pyrimethamine for Prevention of Mother-to-Fetus Transmission of Malaria, Kananga, Democratic Republic of the Congo. Open Journal of Obstetrics and Gynecology, 10, 409-421.

https://doi.org/10.4236/ojog.2020.1030037

Received: November 19, 2019

Accepted: March 23, 2020

Published: March 26, 2020

Copyright $\odot 2020$ by author(s) and Scientific Research Publishing Inc. This work is licensed under the Creative Commons Attribution International License (CC BY 4.0).

http://creativecommons.org/licenses/by/4.0/

\begin{abstract}
Over 90 percent of illness and death attributable to malaria occurs in SubSaharan Africa, frequently among pregnant women and young children. Infection with $P$. falciparum results in high parasitemia percentages and it is the most frequent cause of malaria that results in illness and death in Africa. In areas with holoendemic transmission, such as in most of the Democratic Republic of the Congo (DRC), adults are exposed to malaria every few days or weeks throughout life and, if surviving, have relatively mild bouts of illness because of acquired immunity.
\end{abstract}

\section{Keywords}

Directly Observed Prophylaxis, Sulfadoxine-Pyrimethamine

\section{Introduction}

Over 90 percent of illness and death attributable to malaria occurs in Sub-Saharan Africa, frequently among pregnant women and young children [1]. Infection with $P$. falciparum results in high parasitemia percentages and it is the most frequent cause of malaria that results in illness and death in Africa. In areas with holoendemic transmission, such as in most of the Democratic Republic of the Congo (DRC), adults are exposed to malaria every few days or weeks throughout 
life and, if surviving, have relatively mild bouts of illness because of acquired immunity [2] [3].

Mature $P$. falciparum uniquely sequesters within red blood cells that adhere to the microvascular endothelium of the vascular system and intra-villous spaces of the placenta [2] [3]. The placenta acts as a "privileged site" for parasite multiplication and shields the parasites from clearance by the spleen or by other immunity mechanisms [3]. Pregnant women are more likely to be parasitemic than non-pregnant women in the same community [1]. Younger women in their first or second pregnancy (paucigravid) have a higher risk of adverse outcomes from infection than multigravid women [1] [3].

The most obvious impact of malaria on pregnant women is anemia, with an estimated 10,000 deaths resulting per year from that factor in Africa alone [2] [4].

An estimated 26\% [3] of severe maternal anemia is attributable to malaria and $P$. falciparum malaria can be the leading cause of maternal death [5] [6].

The harmful effects of malaria upon the developing fetus include low birthweight (LBW), a risk approximately doubled if the woman has placental malaria, and neonatal death, implicated in $11.4 \%$ of all neonatal deaths and in $5.7 \%$ of infant deaths associated with LBW [1] [3]. Malaria-associated LBW and intra-uterine growth restriction (IUGR) result from poor fetal nutrition because of the placental infection by the malaria parasites [1]. In areas of stable malaria transmission, malaria is responsible for $8 \%-36 \%$ of prematurity, $13 \%-70 \%$ of IUGR and $8 \%-14 \%$ of LBW, accounting for 75,000 - 200,000 infant deaths per year [1] [7] [8] [9].

Pregnant women can be prophylaxed or treated for malaria. In the mid-1990s, intermittent preventive therapy (IPT) replaced chloroquine-based weekly chemoprophylaxis for the prevention of malaria during pregnancy in most endemic African countries [1]. IPT offered simplicity of administration of the drug although uncertainty remains as to the mode of action.

A small number of anti-malarial drugs have been shown to be safe for both the mother and her fetus. Sulfadoxine-pyrimethamine (SP) (Fansidar ${ }^{\mathrm{TM}}$ ) is the only anti-malarial drug currently used for IPT during pregnancy [10]. In a number of comparative studies over the past decade in countries west and east/ south of the Congo Basin, IPT with SP has been found to be superior to chloroquine administration during pregnancy [11]-[15]. A review in 2003 of anti-malaria drugs during pregnancy found IPT with SP to be "likely to have the best overall effectiveness in preventing adverse outcomes associated with malaria in pregnancy in countries where resistance remains relatively low" [7], however, resistance to SP has been increasing in Africa [6] [10]. Resistance to SP in East Africa is exemplified by 28 -day treatment failure rates of $30 \%$ to $60 \%$ [6] [16] [17].

The Abuja Declaration in 2000 was a commitment for regional African leaders to ensure that $60 \%$ of pregnant women in malaria-endemic areas have access to 
effective prevention programs, including IPT [14]. In 2005, the World Health Organization (WHO) reiterated guidance for the use of SP in IPT, with two doses to be administered after the first trimester [15] [18] [19]. SP is the current recommendation for IPT in the Democratic Republic of the Congo (DRC) [20] [21] [22] [23].

We conducted a study to estimate the effectiveness of SP use as IPT in the Western Kasai province of the DRC.

\section{Methods}

Study Population: The study utilized a catchment design at four maternity clinics that are part of The Christian Medical Institute of the Kasai (IMCK) at Tshikaji, 15 kilometers south of Kananga, DRC. Two clinics were located in villages near The Good Shepherd Hospital, the hub of IMCK, approximately $15 \mathrm{~km}$ south of Kananga; a third clinic was in the city of Kananga, and the fourth clinic was along the southern border of Kananga. The studied population consisted of pregnant women and their newborn infants who enrolled in prenatal care at one of the four clinics.

Study Procedures: Usual prenatal care processes were followed at these clinics and the women delivered their children at the clinic they normally attended, unless complications required delivery at The Good Shepherd Hospital. The medical record for the pregnancy is a card retained by the women. At these clinics, the standard of care was administration of two doses of SP as IPT between 16 and 34 weeks' gestation, or three doses in the same time window if the mother was HIV-positive.

Inclusion criteria for the study protocol included pregnancy, first prenatal visit and intent to deliver at one of the four study sites. Exclusion criteria included allergy to SP and previous anti-malarial treatment during the studied pregnancy. Those who consented had a unique study number added to the medical record card. During the enrollment visit, a questionnaire was administered to solicit demographic and obstetric attributes of the pregnant women including bed net use. Mother's venous blood was tested for the presence of malaria parasites by microscopy using ambient light, and for hematocrit and HIV antibody status. If gestational age was between 16 and 34 weeks, the first SP dose was administered under nurse observation. Women returned one month later for their second SP dose under direct observation. If the woman was HIV-positive, a third dose was administered under observation. First to third doses were administered if the gestation was in the 16 - 34 week windows.

Upon presentation in labor to one of the four study clinics, the delivery portion of the questionnaire was completed. The mother was retested and variables recorded included date of delivery, route of delivery (vaginal or Cesarean section), mother's malaria smear positivity, mother's hematocrit, infant's outcome (alive or stillborn), estimated gestational age, birth weight, cord blood smear for malaria positivity and infant's hematocrit. Women who presented only at delivery formed a "no treatment" group. Their status was confirmed through the 
completion of the questionnaire and abstraction of their obstetric record for any anti-malarial administration. The study was approved by the Institutional Review Boards at the University of Kinshasa and Eastern Virginia Medical School (EVMS).

For the conduct of the study, EVMS investigators participated in the training of clinic personnel and observation of compliance with the study routine through the first patient entered in July 2007. One obstetric nurse was trained to be dedicated to the study under the supervision of Dr. Mubikayi.

\section{Laboratory Testing}

Malaria parasitemia was determined by thick smear exam performed by the clinic laboratory technicians who usually performed the assay. Hematocrit was determined by the use of capillary tubes in a centrifuge. HIV status was determined by the Determine ${ }^{\mathrm{TM}} \mathrm{HIV}-1 / 2$ test.

Quality of malaria smear testing was evaluated by R. Norman Wilkinson, Ph.D., (Lieutenant Colonel, U.S. Army, Ret.) an ex-malariologist, by blinded review of 30 consecutive smears collected in February 2008, at each of the two laboratories performing that assay for the study, under the same conditions as employed by the laboratory technicians. Differences between the technicians and Dr. Wilkinson's results occurred for 2 of the 30 slides in each group scored "rare positive" or " $1+$ " when scored positive by a rater with each of these slides being scored "+/-" or "-/+" by the two raters.

Data Handling and Analysis: The study focused upon specific maternal and infant outcomes: reduction in malaria smear-positivity in the mother, improvement in maternal hematocrit, carriage of pregnancy to term, birth outcome (dead/alive), birth weight, infant malaria smear-positivity, and improved infant hematocrit. Data were entered into EPI INFO v. 6.01 [22]. Three monitoring visits were made in February, June and November 2008 to the study sites by the Norfolk-based investigators, to identify problems with protocol adherence, questionnaire completion and data quality. A final completion visit included a $100 \%$ hardcopy review, to identify any women who may have had a second questionnaire created because of presentation for her first obstetric care at one clinic and delivery at another.

Individual questionnaire variables associated with differences in these outcomes were identified by parametric and non-parametric tests, as appropriate, including t-test and ANOVA for continuous variables, chi-squared and adjusted tests for categorical variables and proportions and McNemar test and KruskalWallis test, where data were non-parametric. Those variables associated with individual outcomes with a $\mathrm{p} \leq 0.20$ were included in a forward, step-wise regression model to assess the independence of variables and the independence of any noted SP treatment effect upon each individual outcome measure [24].

\section{Results}

Subject Enrollment began on July 27, 2007, and the last woman was enrolled for 
prenatal care on July 24, 2008. A total of 2202 women were enrolled: 1,907 who enrolled for prenatal care and 295 who enrolled at delivery (Figure 1). Of those women who enrolled for prenatal care, 1855 received IPT and 52 did not, because of presentation outside the 16 to 34 week window for IPT administration. There were 1105 women who enrolled for prenatal care and did not deliver at one of the four clinics. The percentage of women enrolled at the first prenatal visit who did not deliver at an enrollment clinic increased linearly from $34 \%$ enrolled in August, 2007, to 67\% enrolled in July 2008. There were 1,097 babies born to the remaining 802 women who had enrolled for prenatal care and the 295 women who were enrolled when they presented for delivery. The first birth occurred on September 19, 2007, and the final birth occurred on December 22, 2008. Twin B was excluded for twin deliveries. Of the 1097 births, key information was not recorded for 10 of the births, leaving 1087 births used in the final analysis.

\section{Subject Demographics}

Mothers' Demographic Information: Most (73\%) women lived in a "town", the remainder in a village (Table 1). The percentage of women between 16 and 34 weeks gestation who enrolled was $78.9 \%$, with an additional $7.4 \%$ of women who enrolled prior to 16 weeks. Women (13.7\%) who enrolled after 34 weeks did not receive SP. Bed net use was self-reported by $44 \%$ of the women. Twenty-four women (1.3\%) were HIV-positive. Mean enrollment hematocrit was $34.1 \%$, with $9.5 \%$ being anemic (hematocrit $<30 \%$ ). The average malaria smear-positive rate was $34 \%$. The percentage of women who also delivered at a study clinic who received two doses of SP was $57.7 \%$, the percentage of women who received one dose of SP was $15.0 \%$ and the percentage of women who received no SP was
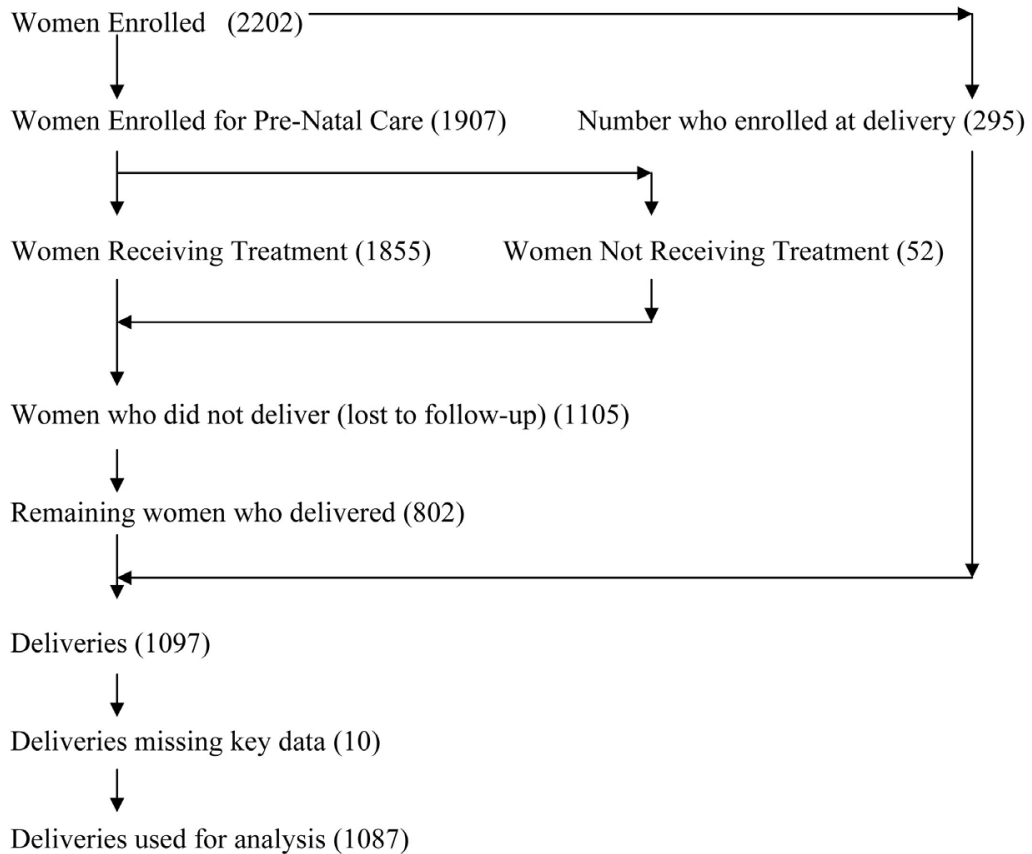

Figure 1. Patient enrollment. 
Table 1. Attributes of mothers and infants.

\begin{tabular}{|c|c|}
\hline Mothers' Demographics & \\
\hline Site (numbers of mothers enrolled) & \\
\hline A & 127 \\
\hline B & 128 \\
\hline $\mathrm{C}$ & 1461 \\
\hline $\mathrm{D}$ & 486 \\
\hline Where live (village or town) & \\
\hline Village & 592 \\
\hline Town & 1609 \\
\hline Age of Mother: Mean \pm 1SD (Range) & $28 \pm 6.9(10-48)$ \\
\hline Use of Bed Nets [\# (\%)] & \\
\hline Yes & $973(44 \%)$ \\
\hline No & $1228(55.8 \%)$ \\
\hline Mothers' Obstetrical History & \\
\hline Gravida: Mean \pm 1SD (Range) & $4.2 \pm 2.8(1-20)$ \\
\hline Para: Mean \pm 1 SD (Range) & $3.1 \pm 2.9(0-14)$ \\
\hline Living Children: Mean $\pm 1 \mathrm{SD}$ (Range) & $2.5 \pm 2.3(0-12)$ \\
\hline Abortions: Mean \pm 1 SD (Range) & $0.3 \pm 0.8(0-11)$ \\
\hline Weeks Pregnant: Mean \pm 1SD (Range) & \\
\hline Overall & $25 \pm 7.5(2-42)$ \\
\hline Enrollment at pre-natal clinic & $23 \pm 6.0(6-40)$ \\
\hline Enrolled at delivery & $39 \pm 1.8(33-42)$ \\
\hline Enrollment GA for SP treatment criteria & \\
\hline$<16$ wks GA & $7.4 \%$ \\
\hline$\geq 16$ wks $G A$ and $\leq 34$ wks GA & $78.9 \%$ \\
\hline$>34$ wks GA & $13.7 \%$ \\
\hline Mothers' Enrollment Laboratory & \\
\hline HIV-Positive [\# (\%)] & $25(1.3 \%)$ \\
\hline Enrolled Hematocrit: Mean \pm 1SD (Range) & $34.1 \pm 3.9(11-50)$ \\
\hline Enrolled Fraction Anemic $(\mathrm{HCT}<30 \%)[\#(\%)]$ & $182(9.5 \%)$ \\
\hline Enrolled Malaria Smear Positive [\# (\%)] & $647(33.8 \%)$ \\
\hline Mothers' Delivery Laboratory & \\
\hline Mothers' Hematocrit: Mean \pm 1SD (Range) & $33.0 \pm 4.2(11-50)$ \\
\hline Mothers' Fraction Anemic (HCT < 30\%) [\# (\%)] & $173(15.9 \%)$ \\
\hline Mothers' Malaria Smear Positive [\# (\%)] & $217(19.9 \%)$ \\
\hline Infants' Delivery Laboratory & \\
\hline Infants' Hematocrit: Mean \pm 1SD (Range) & $47.1 \pm 5.9(20-80)$ \\
\hline Infants' Malaria Smear-Positive [\# (\%)] & $16(1.5 \%)$ \\
\hline Birth Weight: Mean \pm 1 SD (Range) & $3177 \pm 511.6(1000-5400)$ \\
\hline
\end{tabular}


27.2\%. There were no women who received three doses delivered at a study site. At delivery, the average hematocrit was $33.0 \%$ with $15.9 \%$ being anemic. The average for malaria smear-positive rate at delivery was $20 \%$.

There were 1105 women who enrolled for prenatal care but did not deliver at a study site. Women who delivered at a study site had a slightly higher mean age (28.1 versus 27.2 years), malaria smear positivity rate (35.3\% versus $32.9 \%$ ) and a bed net usage rate ( $47.5 \%$ versus $42.4 \%)$. Gestational age at enrollment and hematocrit at enrollment of the two groups were essentially equal. Of the women delivering at a study site, $78.8 \%$ were town residents, while only $66.4 \%$ of those women who did not deliver at a study site were town residents.

Laboratory Attributes of Mother, Infant outcomes and Laboratory Attributes

There was noted a strong seasonal variation of the percent maternal malaria smear positivity at enrollment (Figure 2). The peak value (62\%) occurred during September with a gradual decline until January (16\%) and then a gradual rise to the peak. This trend was noted for mothers' smear positivity at delivery and infants' positive delivery smears, although not as pronounced. The data were adjusted for this seasonality by weighting the various outcomes by each month's mothers' enrollment smear-positivity percentage. The mothers' enrollment anemia status inversely mirrored the enrollment malaria smear positivity trend, with the lowest mean value (16\%) in September and higher values (53\% to 63\%) when mothers were less likely to be malaria-smear positive.

The adjusted data were stratified by the number of doses of SP administered (Table 2). For malaria smear positivity for all mothers at delivery, two doses of SP were associated with a $19 \%$ smear-positivity rate, one dose with a smear-positivity rate of $20 \%$, and no doses with a $25 \%$ smear-positivity rate. The mothers' delivery smear positivity was further stratified by where they lived (town or village). For those mothers who lived in town, the malaria delivery smear-positi-

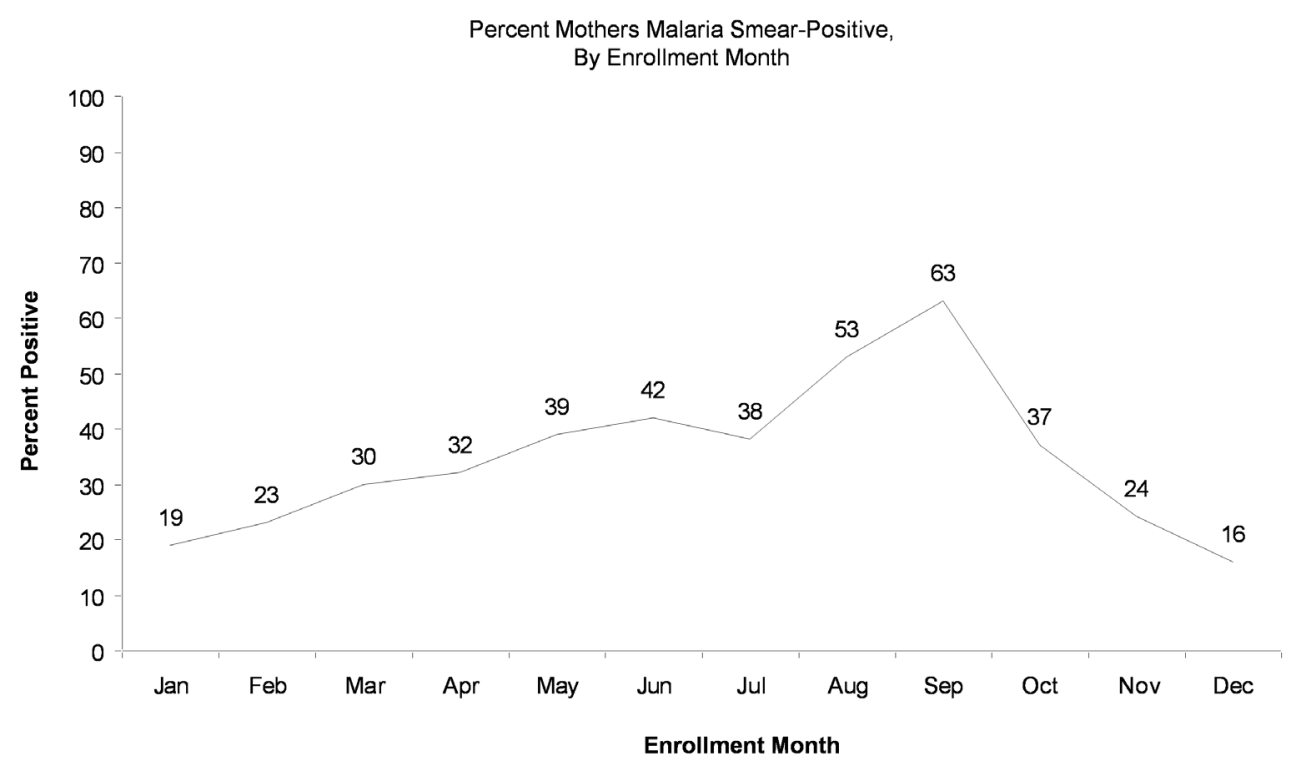

Figure 2. Seasonality. 
Table 2. Estimates of SP reduction in health risks from measures adjusted for seasonality of malaria.

(a)

\begin{tabular}{|c|c|c|c|c|c|c|c|c|}
\hline \multirow[b]{3}{*}{ No. of } & \multicolumn{8}{|c|}{ Malaria Smear at Delivery } \\
\hline & \multicolumn{2}{|c|}{ All Mothers $(\mathrm{N}=$} & \multicolumn{2}{|c|}{ Mothers in Town $(\mathrm{N}=$} & \multicolumn{2}{|c|}{ Mothers in Village $(\mathrm{N}=$} & \multicolumn{2}{|c|}{$\underline{\text { Infant } \#(\mathrm{~N}=}$} \\
\hline & Pos. (\%) & Reduction & Pos. (\%) & Reduction & Pos. (\%) & Reduction & Pos. (\%) & Reduction \\
\hline Doses $^{*}$ & /Total & $\%(95 \% \mathrm{CL})$ & /Total & $\%(95 \%$ CL $)$ & /Total & $\%(95 \% \mathrm{CL})$ & /Total & $\%(95 \% \mathrm{CL})$ \\
\hline \multirow[t]{2}{*}{0} & $74(25)$ & - & $72(29)$ & - & $6(12)$ & - & $5(1.7)$ & - \\
\hline & $/ 297$ & & $/ 174$ & & $/ 50$ & & $/ 297$ & \\
\hline \multirow[t]{2}{*}{1} & $31(20)$ & $22 \%$ & $38(24)$ & $18 \%$ & $4(9)$ & $22 \%$ & $3(1.9)$ & $112 \%$ \\
\hline & $/ 159$ & $(-14-46)$ & $/ 116$ & $(-20-43)$ & $/ 43$ & $(-157-77)$ & $/ 159$ & $(-363-73)$ \\
\hline \multirow[t]{2}{*}{2} & 117 (19) & $26 \%$ & $112(22)$ & $24 \%$ & $5(4)$ & $67 \%$ & $8(1.3)$ & $25 \%$ \\
\hline & /631 & $(4-42)$ & $/ 503$ & $(2-41)$ & $/ 128$ & $(-2-90 \%)$ & 630 & $(-129-75 \%)$ \\
\hline
\end{tabular}

(b)

\begin{tabular}{|c|c|c|c|c|c|c|c|c|c|}
\hline & \multicolumn{9}{|c|}{$\underline{\text { Hematocrit at Delivery }}$} \\
\hline & \multicolumn{3}{|c|}{ Mother $(\mathrm{N}=1087)$} & \multicolumn{3}{|c|}{$\underline{\text { Infant }(\mathrm{N}=1086)}$} & \multicolumn{3}{|c|}{$\underline{\text { Birth Weight }(\mathrm{N}=1097)}$} \\
\hline & $\mathrm{N}$ & Mean & Std. Dev. & $\mathrm{N}$ & Mean & Std. Dev & $\mathrm{N}$ & Mean & Std. Dev \\
\hline 0 & 297 & 33.1 & 3.98 & 297 & 46.8 & 5.58 & 298 & 3124 & 493 \\
\hline 1 & 159 & 32.1 & 3.72 & 159 & 47.2 & 5.57 & 163 & 3155 & 545 \\
\hline \multirow[t]{2}{*}{2} & 631 & 33.1 & 4.16 & 630 & 47.9 & 3.72 & 636 & 3211 & 490 \\
\hline & \multicolumn{3}{|c|}{$p=0.006$} & \multicolumn{3}{|c|}{$\mathrm{p}=0.04$} & \multicolumn{3}{|c|}{$\mathrm{p}=0.01$} \\
\hline
\end{tabular}

${ }^{\star}$ Sulfadoxine-pyrimethamine.

vity rates were $22 \%, 24 \%$ and $29 \%$ for two, one and zero doses of SP. For those mothers who lived in a village, their rates were $4 \%, 9 \%$ and $12 \%$, respectively. Mothers' hematocrit values at delivery, adjusted for seasonality and stratified by the number of doses of SP, were $33.1 \%, 32.1 \%$ and $33.1 \%$ for two, one and zero doses of SP.

The infants' overall average positive malaria smear rate was $1.5 \%$, their mean hematocrit was 47 and their average birth weight was 3177 grams (Table 1). When the infant's delivery data were adjusted for seasonality and stratified by the number of doses the mothers received (Table 2), their resulting malaria smear positivity rate was $8 \%, 3 \%$ and $5 \%$ for two, one and zero doses of SP. Infants' hematocrit at delivery was $47.9 \%, 47.2 \%$ and $46.8 \%$ for two, one and zero doses of SP. Infants' birth weight, similarly adjusted for seasonality and stratified for SP had values of 3211 grams, 3155 grams and 3124 grams, for two, one and zero doses of SP.

Effectiveness Estimates

Logistic regression was performed looking for associations with malaria smear positivity, hematocrit and birth weight (Table 3). For mothers' malaria smear at enrollment: seasonality, mother's younger age, weeks pregnant, fewer gravida, fewer parity, fewer living children, and town residence showed an association 
Table 3. Logistic regression variables.

\begin{tabular}{|c|c|c|c|c|c|c|c|}
\hline & \multicolumn{3}{|c|}{ Malaria Smear Positivity } & \multicolumn{3}{|c|}{$\underline{\text { Hematocrit }}$} & \multirow[t]{2}{*}{ Birth Weight } \\
\hline & $\underline{\text { Mother's }}$ & & & $\underline{\text { Mother's }}$ & & & \\
\hline & $\underline{\text { Enrollment }}$ & $\underline{\text { Delivery }}$ & $\underline{\text { Infant's }}$ & $\underline{\text { Enrollment }}$ & $\underline{\text { Delivery }}$ & $\underline{\text { Infant's }}$ & \\
\hline Seasonality & $\underline{Y}$ & $\mathrm{~N}$ & $\underline{Y}$ & $\underline{Y}$ & $\mathrm{~N}$ & $\underline{Y}$ & $\mathrm{~N}$ \\
\hline Age of Mother & $\underline{\mathrm{Y}}$ & $\mathrm{N}$ & $\mathrm{N}$ & $\underline{\mathrm{Y}}$ & $\mathrm{N}$ & $\mathrm{N}$ & $\mathrm{Y}$ \\
\hline Weeks pregnant & $\mathrm{Y}$ & $\mathrm{N}$ & $\mathrm{Y}$ & $\underline{Y}$ & $\mathrm{~N}$ & $\mathrm{~N}$ & Y \\
\hline Gravida & $\mathrm{Y}$ & $\mathrm{N}$ & $\mathrm{N}$ & $\mathrm{Y}$ & $\mathrm{N}$ & $\mathrm{N}$ & $\mathrm{N}$ \\
\hline Para & $\mathrm{Y}$ & $\mathrm{N}$ & $\mathrm{N}$ & $\mathrm{N}$ & $\mathrm{N}$ & $\mathrm{N}$ & $\mathrm{N}$ \\
\hline Number of Living Children & $\mathrm{Y}$ & $\mathrm{N}$ & $\mathrm{N}$ & $\mathrm{Y}$ & $\mathrm{Y}$ & $\mathrm{N}$ & $\underline{\mathrm{Y}}$ \\
\hline Place of Residence & $\underline{Y}$ & $\underline{Y}$ & $\mathrm{~N}$ & $\mathrm{Y}$ & $\mathrm{N}$ & $\mathrm{Y}$ & $\mathrm{Y}$ \\
\hline Delivery Type & - & $\mathrm{Y}$ & $\mathrm{N}$ & $\mathrm{N}$ & $\mathrm{N}$ & $\mathrm{N}$ & $\mathrm{N}$ \\
\hline Mothers' Delivery Smear & - & - & $\underline{Y}$ & $\mathrm{~N}$ & $\mathrm{~N}$ & $\mathrm{Y}$ & $\mathrm{N}$ \\
\hline Mothers' Enrollment Smear & - & $\mathrm{N}$ & $\overline{\mathrm{N}}$ & $\underline{Y}$ & $\mathrm{~N}$ & $\mathrm{~N}$ & $\mathrm{~N}$ \\
\hline Study Site & $\mathrm{N}$ & $\mathrm{N}$ & $\mathrm{N}$ & $\underline{Y}$ & $\mathrm{~N}$ & $\underline{\mathrm{Y}}$ & $\underline{Y}$ \\
\hline Abortions & $\mathrm{N}$ & $\mathrm{N}$ & $\mathrm{N}$ & $\overline{\mathrm{Y}}$ & $\mathrm{N}$ & $\overline{\mathrm{N}}$ & $\overline{\mathrm{N}}$ \\
\hline Mother's enrolled HCT & $\mathrm{N}$ & $\mathrm{N}$ & $\mathrm{N}$ & - & $\underline{Y}$ & $\mathrm{~N}$ & $\mathrm{~N}$ \\
\hline Weight of Smallest Infant & $\mathrm{N}$ & $\mathrm{N}$ & $\mathrm{N}$ & $\mathrm{Y}$ & $\underline{\mathrm{Y}}$ & $\mathrm{N}$ & $\underline{Y}$ \\
\hline Weight of Largest Infant & $\mathrm{N}$ & $\mathrm{N}$ & $\mathrm{N}$ & $\mathrm{Y}$ & $\mathrm{N}$ & $\mathrm{N}$ & $\underline{Y}$ \\
\hline Mother’s Delivery HCT & - & $\mathrm{N}$ & $\mathrm{N}$ & - & $\mathrm{N}$ & $\underline{Y}$ & $\bar{Y}$ \\
\hline Gestational Age at Delivery & - & $\mathrm{N}$ & $\mathrm{N}$ & - & $\mathrm{N}$ & $\bar{N}$ & $\underline{Y}$ \\
\hline Gender & - & $\mathrm{N}$ & $\mathrm{N}$ & - & $\mathrm{N}$ & $\mathrm{N}$ & $\underline{\bar{Y}}$ \\
\hline Type of Delivery (V or C/S) & - & $\mathrm{N}$ & $\mathrm{N}$ & - & $\underline{Y}$ & $\underline{\mathrm{Y}}$ & $\mathrm{N}$ \\
\hline Preterm Delivery (<37 wks) & - & $\mathrm{N}$ & $\mathrm{N}$ & - & $\overline{\mathrm{Y}}$ & $\overline{\mathrm{N}}$ & $\mathrm{N}$ \\
\hline Use of Bednets & $\mathrm{N}$ & $\mathrm{N}$ & $\mathrm{N}$ & $\mathrm{N}$ & $\mathrm{N}$ & $\mathrm{Y}$ & $\mathrm{N}$ \\
\hline Treated with SP & - & $\mathrm{N}$ & $\mathrm{N}$ & - & $\mathrm{N}$ & $\mathrm{N}$ & $\mathrm{Y}$ \\
\hline Number of SP doses & - & $\mathrm{N}$ & $\mathrm{N}$ & - & $\mathrm{N}$ & $\mathrm{N}$ & $\mathrm{Y}$ \\
\hline Days from last SP dose & - & $\mathrm{N}$ & $\mathrm{N}$ & - & $\mathrm{N}$ & $\mathrm{N}$ & Y \\
\hline Infant's Delivery Smear & - & - & - & - & $\mathrm{N}$ & $\mathrm{N}$ & $\mathrm{Y}$ \\
\hline $\begin{array}{l}\text { (Underscored } \underline{Y} \text { values: } \\
\% \text { variation described) }\end{array}$ & 15 & 3.0 & 7.7 & 9.6 & 1.1 & 6.7 & 16 \\
\hline
\end{tabular}

with greater likelihood of a positive smear on univariate analysis. Of these variables, seasonality, younger age of the mother and town residence showed an independent association in the model and accounted for $15 \%$ of the variation. For mothers' positive smear at delivery: town residence and delivery type were the only variables associated with a positive smear and only town residence was independent, accounting for $3 \%$ of the variation. For infants' malaria smear positivity: seasonality, weeks pregnant and the mothers' delivery smear were significantly associated with a positive smear and seasonality and mothers' positive delivery smear were independently associated with a positive smear, accounting for $7.7 \%$ of the variation.

Logistic regression for factors that influenced the mothers' having a low hematocrit at enrollment resulted in the following variables showing significance: seasonality, younger age of the mother, fewer weeks pregnant, fewer gravida, fewer living children, town residence, mothers' enrollment smear being positive, maternity clinic of enrollment, fewer abortions, smaller weight of the smallest infant, and the smaller weight of the largest infant. Stepwise regression left seasonality, younger age of mother, fewer weeks pregnant, mothers' enrollment being smear positive and maternity clinic of enrollment in the model as indepen- 
dent variables and accounted for $9.6 \%$ of variation. For a lower mother's hematocrit at delivery: fewer living children, mothers' lower enrollment hematocrit, smaller weight of the smallest infant, type of delivery and preterm delivery were significantly associated in univariate comparisons with a low mothers' enrollment hematocrit, smaller weight of the smallest infant, and delivery type remaining in the multivariate model, with a $1.1 \%$ variation described. For a lower infants' hematocrit: seasonality, fewer living children, town residence, mothers' positive delivery smear, maternity clinic of enrollment, a lower mothers' delivery hematocrit, delivery type and lack of use of bed nets were associated in univariate comparisons and seasonality, maternity clinic of enrollment, mothers' lower delivery hematocrit and delivery type remained in the final model contributed $6.7 \%$ to the variation. Finally, for a lower birth weight: younger age of the mother, weeks pregnant, fewer living children, town residence, maternity clinic of enrollment, smaller weight of the smallest previous infant, smaller weight of the previous largest infant, mothers' lower delivery hematocrit, younger gestational age at delivery, male (?) gender, treatment with SP, number of doses of SP, days from last SP dose and infants' delivery smear showed positive association in the model, with only number of living children, study site, weight of smallest infant, weight of largest infant, gestational age at delivery, and gender remained with $16 \%$ variation described.

\section{Adjusted Estimates of Effectiveness of SP}

Estimates of SP reduction in health risks, when adjusted for seasonality of malaria, are tabulated in Table 2. For mothers' delivery malaria smear positivity, one dose of SP was associated with a $22 \%$ (95\% CI: 9.3 - 14.46) reduction, while two doses resulted in a statistically significant $26 \%$ (4.42) reduction. For mothers in town, the percent reduction in malaria smear positivity was $18 \%(-20.43)$ for one dose and a statistically significant $24 \%$ (2.41) for two doses. For mothers in the village, the one and two dose reductions in smear positivity were $22 \%$ and $67 \%$, respectively; the number $(\mathrm{N}=15)$ of positive smears in this group was small, erratic because of small numbers, and not statistically significant. For infants, the SP reduction in malaria smear positivity was $112 \%$ and $25 \%$, respectively.

\section{Discussion}

We conducted a study to estimate the effectiveness of SP used as IPT in the Western Kasai province of the Democratic Republic of the Congo (DRC). Only birth weight demonstrated association with SP doses in univariate analysis, but this effect dropped out of the model in multivariate analysis when the mother's smallest previous infant birth weight was included. While estimates of reduction in health risks with different doses of SP corrected for seasonality appeared to show some efficacy, when these data were analyzed with logistic regression, the effect of SP administration did not remain significant. The most that the factors analyzed contributed to variation in logistic regression analysis was $16 \%$, leaving a large amount of variation apparently due to a set of unmeasured factors af- 
fecting the outcomes measured.

Strengths of study/unique features

The large size of the study, with over 2200 women enrolled and over 1000 deliveries, provides a solid set of data for the analysis. The data provide an accurate snapshot of maternal care in this part of the DRC and is the first significant study on the effectiveness of SP in this part of the DRC. The execution of the government recommended prenatal care protocol was captured over a period of a year, yielding an accurate portrayal of the clinical care and outcomes in the Western Kasai region of the DRC. A specific strength was the catchment design: all eligible women received directly observed therapy and their portable clinic record allowed treatment given by another clinic to be recorded.

Weaknesses of study

- Large number (57.9\%) fraction lost to follow up.

- Insufficient questions relating to ITN use, non-maternity access to drugs.

- Light microscopy.

Compared with other studies of malaria in sub-Saharan Africa, the congenital rate in this study $(1.6 \%)$ is near the low range $(0 \%-0.7 \%)$ of published studies with some published data reporting rates as high as $37 \%$. Maternal malaria parasitemia rates of $34 \%$ and $18 \%$ (enrollment and delivery, respectively) recorded in this study are comparable to published rates of $24.8 \%$ to $54.4 \%$ [14] [23] [24] [25] [26].

Study implications

- The lack of SP efficacy portends possible resistance to this drug in the Western Kasai region of the DRC.

- Resources directed to congenital malaria prevention need to be redirected to a more effective means.

- Other treatment options for malaria prophylaxis for pregnant women need to be explored.

Required future investigation

- Increased number of doses?

\section{Conflicts of Interest}

The authors declare no conflicts of interest regarding the publication of this paper.

\section{References}

[1] Desai, M., ter Kuile, F.O., Nosten, F., et al. (2007) Epidemiology and Burden of Malaria in Pregnancy. The Lancet Infectious Diseases, 7, 93-104. https://doi.org/10.1016/S1473-3099(07)70021-X

[2] Rogerson, S.J. and Menendez, C. (2006) Treatment and Prevention of Malaria in Pregnancy: Opportunities and Challenges. Expert Review of Anti-Infective Therapy, 4, 687-702. https://doi.org/10.1586/14787210.4.4.687

[3] Yartey, J.E. (2006) Malaria in Pregnancy: Access to Effective Interventions in Africa. International Journal of Gynecology \& Obstetrics, 94, 364-373. 
https://doi.org/10.1016/j.ijgo.2006.04.026

[4] Nosten, F., McGready, R., Looareesuwan, S. and White, N.J. (2003) Editorial: Maternal Malaria: Time for Action. Tropical Medicine \& International Health, 8, 465-467. https://doi.org/10.1046/j.1365-3156.2003.01067.x

[5] White, N.J. (2005) Intermittent Presumptive Treatment for Malaria. PLOS Medicine, 2, 28-33. https://doi.org/10.1371/journal.pmed.0020003

[6] Barnett, E.D. (2004) Malaria. In: Feigin, R.D., et al., Eds., Textbook of Pediatric Infectious Diseases, 5th Edition, Saunders, Philadelphia, 2714-2729.

[7] Crawley, J. and Nahlen, B. (2004) Prevention and Treatment of Malaria in Young African Children. Seminars in Pediatric Infectious Diseases, 15, 169-180. https://doi.org/10.1053/j.spid.2004.05.009

[8] Newman, R.D., Parise, M.E., Slutsker, L., Nahlen, B. and Steketee, R.W. (2003) Safety, Efficacy and Determinants of Effectiveness of Antimalarial Drugs during Pregnancy: Implications for Prevention Programmes in Plasmodium falciparumEndemic Sub-Saharan Africa. Tropical Medicine \& International Health, 8, 488-506. https://doi.org/10.1046/j.1365-3156.2003.01066.x

[9] Brentlinger, P.E., Behrens, C.B. and Micek, M.A. (2006) Challenges in the Concurrent Management of Malaria and HIV in Pregnancy in Sub-Saharan Africa. The Lancet Infectious Diseases, 6, 100-111. https://doi.org/10.1016/S1473-3099(06)70383-8

[10] Cohen, J. (2003) Epidemiology. Mothers' Malaria Appears to Enhance Spread of AIDS Virus. Science, 302, 1311. https://doi.org/10.1126/science.302.5649.1311a

[11] terKuile, F.O., van Eijk, A.M. and Filler, S.J. (2007) Effect of Sulfadoxine-Pyrimethamine Resistance on the Efficacy of Intermittent Preventive Therapy for Malaria Control during Pregnancy. JAMA, 297, 2603-2616.

https://doi.org/10.1001/jama.297.23.2603

[12] Tiono, A.B., Ouedraogo, A., Bougouma, E.C., et al. (2009) Placental Malaria and Low Birth Weight in Pregnant Women Living in a Rural Area of Burkina Faso Following the Use of Three Preventive Treatment Regimens. Malaria Journal, 8, Article No. 224. https://doi.org/10.1186/1475-2875-8-224

[13] Brian, V., Denoeud, L., Massougbodji, A., et al. (2008) Efficacy of Intermittent Treatment versus Chloroquine Prophylaxis to Prevent Malaria during Pregnancy in Benin. The Journal of Infectious Diseases, 198, 594-601. https://doi.org/10.1086/590114

[14] Tukur, I.U., Thacher, T.D., Sagay, A.S., et al. (2007) A Comparison of Sulfadoxine-Pyrimethamine with Chloroquine and Pyrimethamine for Prevention of Malaria in Pregnant Nigerian Women. The American Journal of Tropical Medicine and Hygiene, 76, 1019-1023. https://doi.org/10.4269/ajtmh.2007.76.1019

[15] Asa, O.O., Onayade, A.A., Fatusi, A.O., et al. (2008) Efficacy of Intermittent Preventive Treatment of Malaria with Sulphadoxine-Pyrimethamine in Preventing Anaemia in Pregnancy among Nigerian Women. Maternal and Child Health Journal, 12, 692-698. https://doi.org/10.1007/s10995-008-0319-3

[16] Bertin, G., Ndam, N.T., Jafari-Guemouri, S., et al. (2005) High Prevalence of Plasmodium falciparumpfcrt K76T Mutation in Pregnant Women Taking Chloroquine Prophylaxis in Senegal. Journal of Antimicrobial Chemotherapy, 55, 788-791. https://doi.org/10.1093/jac/dki097

[17] Democratic Republic of the Congo Ministry of Health Secretariat-General. HealthSystem Strengthening Strategy (Translated from French). 
[18] Sub Saharan Africa HIV \& AIDS Statistics. http://www.avert.org/subaadults.htm

[19] World Health Organization (2004) A Strategic Framework for Malaria Prevention and Control during Pregnancy in the African Region. WHO Regional Office for Africa, Brazzaville.

[20] World Health Organization Regional Office for Africa (2005) Recommendations on the Use of Sulfadoxine-Pyrimethamine (SP) for Intermittent Preventive Treatment during Pregnancy (IPT) in Areas of Moderate to High Resistance to SP in the African Region.

[21] Kuile, F.O., Terlouw, D.J., Phillips-Howard, P.A., et al. (2003) Reduction of Malaria during Pregnancy by Permethrin-Treated Bed Nets in an Area of Intense Perennial Malaria Transmission in Western Kenya. The American Journal of Tropical Medicine and Hygiene, 68, 50-60. https://doi.org/10.4269/ajtmh.2003.68.50

[22] Roll Back Malaria (RBM) Partnership (2005) Democratic Republic of the Congo Country Profile. http://www.rbm.who.int/wmr2005/profiles/drc.pdf

[23] Hosmer, D.W. and Lemeshow, S. (2000) Applied Logistic Regression. 2nd Edition, John Wiley \& Sons, Hoboken, 392 p. https://doi.org/10.1002/0471722146

[24] Coulibaly, S.O., Nezien, D., Traore, S., et al. (2006) Therapeutic Efficacy of Sulphadoxine-Pyrimethamine and Chloroquine for the Treatment of Uncomplicated Malaria in Pregnancy in Burkina Faso. Malaria Journal, 5, 49. https://doi.org/10.1186/1475-2875-5-49

[25] Malaria Statistics in Sub-Saharan Africa.

[26] Oluwu, J.A., Sowunmi, A. and Abohweyere A.E.J. (2000) Congenital Malaria in a Hyperendemic Area: A Revisit. African Journal of Medicine and Medical Sciences, 29, 211-213. 